\title{
POSITIVE CONSEQUENCES OF COVID-19 PANDEMIC: REFLECTIONS BASED ON UNIVERSITY STUDENTS COMMUNITY IN BANGLADESH
}

\author{
RAHMAN Md. Mizanur ${ }^{1}$, RAHAMAN Md. Saidur ${ }^{2}$, SALAMZADEH Aidin ${ }^{3}$, JANTAN \\ Amer Hamzah ${ }^{4}$ \\ ${ }^{1}$ BRAC Business School, BRAC University, Dhaka (BANGLADESH) \\ ${ }^{2}$ Metropolitan University, Sylhet (BANGLADESH) \\ ${ }^{3}$ Faculty of Management, University of Tehran (IRAN) \\ ${ }^{4}$ City Graduate School. City University (MALAYSIA) \\ E-mails:mizanmgt@gmail.com; saidurmgt@gmail.com; salamzadeh@ut.ac.ir;mizanmgt@gmail.com
}

\begin{abstract}
The fundamental aim of this study is to demonstrate the positive consequences of the COVID-19 pandemic while everyone else is talking about COVID-19's adverse effects. Researchers collected data through FGD (Focus Group Discussion) via an internet platform from April 2021 to June 2021. FGD was conducted with final-year undergraduate students from Bangladesh's Sylhet division. We purposively selected 20 students who have good knowledge about the consequences of COVID-19 and who were voluntarily involved at the university's different social clubs. According to this study, COVID-19 has positive impacts on people's life. People spent crucial time with their families, explored their interests, developed a range of new skills, and appreciated the need for sanitation, hygiene, and social separation. Nature recovers energy, and greenhouse gas emissions are significantly reduced to protect the ecosystem. Among other notable positive effects, people build religious learning's in conjunction with crime reduction notions. Researchers study a particular division (Sylhet) of a country, which may differ from that of other cultures and countries. As a result, generalizing the research findings is complex; more research in different divisions of Bangladesh, countries, and cultures is required. The study outcomes are intended to assist the community in building positive psychology to confront the covid-19 and establish a new normal and a guideline for dealing with any impending pandemic. To the best of our knowledge, this is one of the most comprehensive studies on the positive effects of covid-19, as well as a guideline for dealing with any pandemic that may occur in the near future.
\end{abstract}

Keywords: COVID-19; Bangladesh, pandemic, positive, students

\section{JEL:I10}

DOI: 10.5937/intrev2103083R

UDC: $616.98: 578.834]: 165.73$

316.613:159.947.23

159.947.24-057.875(549.3)

COBISS.SR-ID 55093513 


\section{INTRODUCTION}

Coronavirus (COVID-19) was unknown to the rest of the globe before 2019[1].For everyone, the deadly virus has become a matter of discussion and anxiety [2][3][4] "Corona" is derived from the Latin word "corona," which meaning "crown" [5]. The first novel type of coronavirus was discovered in Wuhan, Hubei Province, China, in 2019 [6][7][8][9][10]. On the other hand, in Bangladesh, COVID-19 was discovered for the first time on March 4, 2020. Furthermore, on March 7, 2020, the Institute of Epidemiology, Disease Control, and Research (IEDCR) announced that three persons had been infected[11][2].The Bangladeshi government then recommended civilians go for home quarantine. According to the Department of Health Bulletin, a total of 15, 44,238 persons had been discovered infected across the country as of September, 2021. As of now, 27,251 people have died in Bangladesh [12]. The impact of COVID-19 is so massive that it has changed the world and human behavior. Many changes are already visible, but Covid-19 has made these changes much faster and more permanent for the world [13][14] [15]. Quite rightly, all of us have been observing the negative aspects of the Corona Virus and its complications, but as we know, every coin has two sides similarly; this pandemic has some positive aspects [16][17]. The coronavirus has positive social consequences on people's daily lives. Positive social consequences, which can be defined as "the science and practice of promoting well-being," has gained prominence in recent years [18][19][20][21]. This study applied the novel notion of positive social consequences to help people regain mental strength throughout the COVID-19. With the government shutting down all kinds of organizations and industries, people are getting more time to spend with their families, thereby strengthening family ties. In terms of medical emergencies, there have been more improvements in increasing medical beds, availability of helpline, and so. More of the positive aspects of the Corona Virus continues to buzz around; for instance, people have been more conscious about time and avoiding unnecessary travel and meetings. The pandemic has highlighted the time we waste traveling and the economic costs associated with it reduced. Seemingly our entire lifestyle changed, and we are more focused on practicing better hygiene; we are now more aware of how important it is to keep ourselves clean [22]. Few good habits include covering the mouth when we cough or sneeze, sanitizing our hands before and after touching anything [23]. Moreover, when we look closer to a fancy side of lockdown because of this pandemic, we could observe that many of us have learned new skills about our interests and hobbies, such as cooking, art, dancing, etc., through YouTube or other browsing sites. Last but not least, we, including children to older people, are now more sensitive about health hygiene, proper diet, and being empathetic towards every one of us during our difficult times[23]. The majority of us are now concerned more about diet patterns to boost immunity and necessary medical kit to have at home etc.[22] .Alongside, we have been learning and adapting to novel processes to better our lifestyle and defeat the deadly virus, and we have encountered the 'New Normal' along the way. It appears that technology has played a critical part in practically every area, including business, education, and other aspects, at such a trying time. During the quarantine time, technology has commanded our full attention to governing our lives during and after the quarantine. Although technology was on the right track before the epidemic, individuals are now more inclined to adapt quickly to technology. As a result, people are now trying to find out the positive effects of this virus without thinking about the adverse effects. In this challenging corona time, we can see that COVID-19 gifts us some positive sites if we notice carefully. With the COVID-19 pandemic somehow, we benefit socially, technologically, educationally, ethically, and environmentally. COVID-19's positive benefits on education [24](Magomedov et al., 2020), the environment [25](Khan et al., 2020; [26]Ming et al., 2020; [27]Lau et al., 2020), economy have all been studied extensively [28] in the context of different countries. But, to the best of our knowledge, researchers and academicians in Bangladesh have not focused on these crucial issues until today. Academics in Bangladesh should dedicate significant attention to the topic, despite being thoroughly researched or generalized to the broader public. As a result, the primary goal of this paper is to determine the favorable benefits of the pandemic Covid-19. Researchers devised a set of critical questions for the focus group to answer to achieve the primary goal. The study's findings should help the community build positive social psychology to combat COVID-19 and look forward to a new normal. Below is a sample of the questions.

- What do you know about covid-19?

- Are there any positive effects of covid 19?

- Society gains huge change from covid-19. Do you believe it?

- Can you compare other benefits with regards to technology?

- What are the other's viewpoints, for what we can thank covid-19?

We reviewed the COVID-19 history in the first half of the introduction and the positive interests of COVID-19 in the second part. Later on, with a general discussion of the current situation and positive lessons learned during COVID-19. We concentrated on identifying the research gap and setting objectives to fill to research the last section. The methodology of the study, on the other hand, comes next. 


\section{METHODOLOGY}

\section{RESEARCH DESIGN}

In this study, we have used Focus Group Discussion (FGD) to generalize the research findings. FGD is a valuable method since it can help get complex data quickly and at a low cost in a short period [29][30]. We believed that FGD has the potential to elicit and draw on respondents' attitudes, feelings, beliefs, experiences, and reactions in ways that other approaches such as observation, one-on-one interviews, or questionnaire surveys cannot. Respondents are selected from the university to acquire detailed information pertinent to the study's objectives.

\section{SAMPLE SIZE}

We purposively selected 20 students who have good knowledge about the consequences of COVID-19 and who were voluntarily involved at the university's different social clubs in the Sylhet division. There is an old proverb in research that "the more data points, the better." Crouch \& McKenzie (2006) suggest that having fewer than twenty (20) participants in a qualitative study helps the researchers shape and sustain a strong relationship, which promotes the "open" and "frank" exchange of information. Furthermore, when the research scope is narrow and the responders are homogeneous, only 6-12 people can understand the situation [31].

\section{DATA COLLECTION AND ANALYSIS PROCEDURE}

Researchers set up four focus group discussions in the first phase, each with five participants chosen at random by zoom breakout. Researchers reviewed the concepts, the summary from the inclusive interview [32] and their perspectives on COVID-19's positive effects during the focus groups discussion. In that platform (Zoom), the respondents from each group shared their opinions on the positive and negative social consequences of COVID-19. In this study, with permission from the respondents, the recorder of Zoom was active to record the interview during the interview session. For two major reasons, the Zoom platform was chosen. Due to COVID-19, it was difficult to approach students directly at first because educational institutions were closed. Second, because the interview was recorded, the material was easy to transfer and save for further data analysis procedures. The discussions were placed in both English and Bangla. In the end, it is the data manually analyzed. Besides, we acquired secondary data from journal articles, published papers, books, and numerous websites.

\section{ETHICAL CONSIDERATION}

The researchers provided a consent form with the participants at the start of the interview session. It states that not all of your demographic information is disclosed and that the information relating to the research is utilized for research purposes solely. The demographic information of the participants is therefore not stated anywhere. In addition, before using the data for our study goals, we got the appropriate consent from all respondents.

\section{ANALYSIS AND DISCUSSIONS}

We are all focusing on the negative aspects of COVID-19, which is still happening continuously, but just as every coin has two sides, this pandemic also has some positive aspects. The entire world was under lockdown to prevent the virus from spreading rapidly. Even though the lockdown has physically separated friends and relatives, the time we spend with our family is priceless. During this lockdown, fewer automobiles were on the road, which helped reduce air and water pollution. Besides that, the majority of us are now more worried about sanitation, our eating habits to increase immunity, and the medical equipment we need at home, among other things[22]. These positive effects are explained below in brief with the respondents' view. 


\section{POSITIVE CONSEQUENCES IN THE EDUCATION SECTOR}

In the initial stage of the COVID-19 pandemic, all educational institutions worldwide were declared closed by the respective government to prevent the infection. Students are encouraged to relocate their residences, keep them safe, and continue their education online. In Bangladesh, still (19-09-2019), students are doing online classes by living comfortably in their own homes despite going to institutions. Both institutions and students are getting some advantages during this pandemic. In terms of institution, there are no maintenance expenses and other costs. Students also benefit from having some tuition discounts. Besides, They do not have to pay the hostel fees, and they do not have to bear any other expenses. Maximum respondents articulated,

'The emergence of online classes during the pandemic has helped me to better and easy access to attend classes. I didn't feel much hassle to join the class online compared to the physical classes. [G\#1, G\#2, \& G\#4]

The education system has been hit hard by the pandemic. There are still (19-09-2019) shut down of schools, colleges, and universities due to COVID-19 results; there is uncertainty regarding education. However, this situation has some benefits; for example, the pandemic has made a pathway for Elearning[33].Most of the members' viewpoint is,

'We are getting high quality and free online courses more than ever. Recently popular Elearning platform "Coursera" provided free access to its premium courses to thousands of university students worldwide. We are always encouraged to stay home. As a result, we have time for learning life skills such as cooking, washing, and swimming'. [G\#3 \& G\#4]

Suppose we have the right technologies for proper penetration. Online learning can be a useful option for education in that case. Some research findings showed that students retain 25-60 percent more elements on average compared to the physical classroom when studying online [34]. This statement demonstrates the success of the e-learning program. A member avowed,

"One of my friends from a leading university concluded that ever since online lessons have introduced, his class attendance has increased. He is regular in classes after the commencement of online classes. [G\#3]"

Because of the pandemic situation, all educational institutions in Bangladesh remained close since 23rd March 2020. Initially, the thought was that students would deprive of all academic activities. However, the pandemic has made a pathway for E-learning [22] for both developed and developing countries. Thus, Bangladesh has also shifted the online education system for an extended time. In this situation, both students and faculty members are learning and adapting to these new things. Therefore, to some extent, COVID-19 has positive effects on education.

\section{POSITIVE CONSEQUENCES IN THE ENVIRONMENT SECTOR}

While individuals deal with COVID 19 and have begun to isolate themselves within their homes, the environment takes advantage of this opportunity to rejuvenate itself. For the past three decades, the entire world has been concerned about global warming; temporarily shutting down production factories and automobiles can help reduce global warming and regenerate the environment even if every country agrees on this point. For instance, just a few days ago, we saw in numerous publications and media stations that dolphins had arrived in the Bay of Bengal. Wildlife, like air and water, has begun to notice changes. In a week, more than 16000 birds had returned to their respective nests[35]. The water pollution of the river has also been reported to have diminished to some amount. A respondent asserted,

One of the amazing things about it is that, yeah, the earth rebounds back as people all across the world take COVID 19 safeguards[G\#1 \& G\#4].

According to a recent study, the COVID-19-induced lockdown has considerably reduced global pollutant levels. Pollution levels (water, air) in New York have decreased by more than half this year compared to the previous year due to several actions to stop the virus from spreading [36]. It is possible that decreasing global oil demand resulted in even lower emissions. According to Sky.com, if China's economic fall continues at its current rate, "up to 100,000 premature deaths due to air pollution in China might be saved over the next year." According to the Centre for International Climate Research in Oslo, "like the burning of fossil fuels has declined, air quality has greatly improved, and the impact will be seen worldwide". 
"Carbon emissions level went down due to closure of factories, domestic flights and most cars were parked because people stayed at their homes to prevent the spread of the disease”. [G\#3 \& G\#4].

Furthermore, because there are no tourists, a large number of animals walk along the roadways. Elephants, deer, and penguins [37]can wander and relax because the streets are mostly unoccupied. The wildlife appears to be pleased because there are almost no visitors/tourists on the sea beach. Many dolphins have been photographed playing in the sea, and the images have gone popular on social media. So,

'The world healed itself as a result of the worldwide lockdown. Because of the ban on industrial work and global transportation, there is less air pollution all around the world. This reduction in air pollution will help to ensure a healthy global environment in the future.' [G\#4]

Also, in most countries, noise levels have decreased significantly. A clamor decrease has been induced by reducing the use of private and open transportation and commercial activity. Noise is an unwanted sound that has a jarring effect on communication. The lockdown also impacted the maritime ecosystem, as all kinds of transportation within the aquatic environment were ceased, and the level of contamination produced by human activities was drastically reduced. Concerning all of these difficulties, the discovery of blue sky during a moment of global lockdown inspired people to think positively about a clean and better environment, resulting in a significant change in the biological system, says one participant.

"It's sort of cool that it's happening at a time when everyone is under a lot of stress, and reconnecting with nature can help them deal with some of that weight," [G\#1 \& G\#4].

The new normal life should be characterized by a "clean and natural environment," in which there is no pollution, people are accustomed to seeing clear skies, there is no carbon emission, and nature reclaims its original beauty. So now is the time to reconsider the post-Covid-19 era, in which we must work together to maintain nature clean and livable.

\section{POSITIVE CONSEQUENCES IN SOCIAL BONDING}

During the COVID-19 and lockdown, staying at home positively impacted our bond and sustained good relationships. Life before this pandemic, we were so busy that we somehow forgot to spend time with our family. Spending great moments with our family made the lockdown time worthy and extremely memorable. Parents have begun to spend time with their children, which was previously lacking from their hectic daily schedule. Three generations of a family are sitting together and enjoying each other's company due to the lockdown

In my view actually, when I'm in normal life I didn't get time for my family but in this pandemic situation, I gave full time to my family its most wonderful gift that Covid-19 give us. [G\#2 \& G\#4].

It is true we could not meet our friends and relatives, but we could connect with them through video calls. After that, if we were lucky enough, then go for family vacations [23]. Most people cannot find time for their hobbies in their regular schedules, but now that they have these mandatory holidays, they can do so. Overall, communication amongst relatives has vastly increased.

On normal days we all have been busy with our work life, for that reason' many of us have lost those real, genuine relationships with our family and with our loved ones. It could have been the busy schedules \& rushing to be in urgent meetings, class, coaching's, and so on. After that, if we were lucky enough then go for family vacations. [G\#1 \& G\#4].

Corona has compelled people to stay at home for an extended period. People believe that a significant portion of the family member assisted each other with domestic duties. However, the news was not published because of the cut. Why simply husband and wife? Because most cases, the child's bond with their parents has grown more potent due to the epidemic. Who is more unfortunate than those who could not take advantage of this opportunity to build a relationship? Such as (a respondent mentioned)

"People become more generous and rich people are helping the poor who are facing hardship arising from the pandemic. They are changing selfishly materialistic attitudes." [G\#3 \& G\#4].

During the epidemic, the poor were in danger due to food scarcity, and the government stepped in to support them. The government and many ordinary citizens and non-governmental organizations (NGOs) stepped forward to offer food and other necessities. Furthermore, it is very incredible that some people who could not aid financially provided free labor services. We are immensely proud of the doctors, volunteers, and police 
officers who worked tirelessly to save the country's people during this challenging period. By working together to eradicate the coronavirus, we once again demonstrated that "unity is strength." This pandemic catastrophe has given us a crucial lesson: we can overcome any problem if we work together.

\section{POSITIVE CONSEQUENCES IN HEALTH AND HYGIENE}

Doctors, academics, and public health authorities believe the pandemic also provides a unique window into some favorable health impacts that have resulted from fundamental shifts in human behavior. Furthermore, the epidemic may encourage people to accept and act on public health messages because it has been seen that persons who have already been diagnosed with various ailments are better able to control the coronavirus. As a result, people's interest in healthy living has grown. The respondent from a group notice:

My study says that it is our duty to until our death to save the whole world to practice better health and hygiene we need to take good food wash our hands with soap and using a mask when we are in the outside environment, our little afford one day will become successfully control the coronavirus. [G\#1 \& G\#3].

During the COVID-19 situation, people are more health-conscious; they always think to keep themselves clean, use masks, PPEs, and hand sanitizers .For leaving a healthy life in the future, people are used to abstaining from shaking hands to greetings. People do not forget to go outside without covering masks, split the cough properly, and sanitize hands before and after touching anything. We also understood the importance of having strong immunity to fight against such diseases.

Well, it's incredible that we got to know how significant it is to keep ourselves clean and maintain social distance and we all aware of how to do that more hygienically. That's why we took special care of our health and hygiene in order to avoid attacking by corona virus. Now, for a healthy society we avoid shaking hands, we use mask and sanitize our hands frequently. [G\#2 \& G\#3].

People are currently living cleaner lives than they have ever been. The city's shops, restaurants, and alleyways are all being kept cleaner than previously.

People, I believe, will stick to their new routines for at least a few years. [G\#1 \& G\#4].

People have become more "health-conscious" as the coronavirus progresses since health care and medication will take precedence. Masks, gloves, and personal protective equipment (PPEs) may be ubiquitous in places like shopping malls, offices, and hospitals, but it all depends on where you reside.

\section{REDUCTION OF CRIMES AND INCREASING CONCERN ON ETHICAL ISSUES AS POSITIVE CONSEQUENCES}

There is a substantial downward fall in illegal activities. People who cause harm to others inroads are also locked at home, so there is a huge decline in crimes such as hijacking, kidnapping, drug addiction, alcoholism, gambling, prostitution, violence, etc. Moreover, road accidents could not occur as the transportation is off, so roads are empty. As a result of the seasonal crime, residents and police will benefit from these restrictions. The graph of crime rate has been moving downward for the past few days. As a result of the lockdown, there has been a reduction in street violence, catastrophic traffic accidents, and increased police protection. Closed borders have helped to keep robbery and vehicle theft to a minimum. The city's crime rate has reduced considerably.

See, everything and everywhere are closed now, so, it should be reduced the crime now. [G\#1 \& G\#2].

In the second half of March, most crimes, such as harassment, declined by half, while a few others, such as robbery, kidnapping, and extortion, decreased by 80 percent. Under-aged drunkenness has vanished mainly as a result of the shutdown. As more senior citizens choose to remain at home, the number of crimes committed against them has plummeted. Criminal activity in the city, such as eve-teasing, snatching, and pickpocketing, has practically decreased during the lockdown period.

We have discovered some ethical benefits for doctors. They are aware that governments will not be held accountable for how patients are treated based on the circumstances and conditions that were acceptable at the time. On the other hand, the government has taken legal action against persons who appear to be breaking regulations that could lead to fatal infections. By 5 p.m., all businesses, shopping malls, and department stores, for example, are closed. So, 
'There are some ethical issues for doctors because they are told they will not be chastised by the government or the public if they treat people based on the situations and circumstances at the moment.' [G\#3\& G\#4]

Due to this pandemic, COVID-19 coronavirus has created many changes to public benefits and more. COVID-19 also has some legal benefits. Many positive changes in Bangladesh are made during this pandemic, such as general people are getting emergency housing facilities with no utility fee, tenants are getting proper rights, and property taxes are free, and so on.

\section{POSITIVE CONSEQUENCES IN THE TECHNOLOGICAL SECTOR}

Undoubtedly, we can say the technology companies are ruling the world. Without technology, the whole world would have been different during the Covid-19 lockdown. Almost everything was running because of the advancement of technology. We turned out more techno-savvy and did much of this online such as a webinar, online classes, online transactions, online medicine delivery, etc. Technology adoption turns out to be much faster. The students are doing online courses with smartphones. The students and teacher could continue the classes through apps.

"The emergence of technology during the pandemic has helped me to better and easy access to attend classes. I didn't feel much hassle to join the class in online compared to the physical class. " [G\#2 \& G\#3].

Due to the lockdown, we could not meet our friends and relatives, but we could connect with them through chats and video calls. The use of the internet is the only source of connecting to others by staying at home. The usage of some products massively increased, such as Zoom, Google Meet, Microsoft, etc. Organizations are performing virtual meetings with employees through these apps. Moreover, for entertainment purposes, we tend to spend most of our time on Instagram, YouTube, Facebook, etc. For safety, we chose online transactions rather than going to banks. Almost all our payments and receipts were through internet banking or mobile wallets.

"During the lockdown, people tend to attend online meetings for their work which were designed to keep shorter as it consumes less time and it's a more effective way to deal with it." [G\#1 \& G\#4].

Technology will dominate the planet during and after this pandemic. Our reliance on the internet and communication technology, social media, smartphone apps, and other technologies has grown due to the shutdown. Other major technology platforms, such as YouTube, Instagram, Facebook, Messenger, WhatsApp, LinkedIn, Amazon, Google, Microsoft, Alibaba, and others, have influenced our high-tech and artificial intelligence adoption. E-commerce attracts a large number of customers in a short period. The reliance on e-commerce has risen substantially, with Facebook lately launching shops and LinkedIn updating its capabilities, all in response to public demand [38][39].

\section{STRENGTHS AND CONTRIBUTIONS OF THIS RESEARCH}

The current study is unique; to the best of our knowledge, researchers and academicians in Bangladesh have not focused on these crucial issues until today regarding the students' perceptions. In terms of the contributions, the study's findings are meant to aid the community in developing positive psychology to face the covid-19 and establish a new normal and a guideline for dealing with any impending pandemic.

\section{CONCLUSION}

COVID-19 is still being fought in countries worldwide, and we can only hope that it will be eradicated one day. We must learn from this pandemic and be prepared to deal with similar situations in the future. People should take care of their physical and mental health by getting enough rest, exercising, or practicing yoga. This crisis demonstrated the need to strengthen our healthcare system and clinical research and alerted us to some unexpected benefits. We can see how weak or strong our medical system is due to the COVID-19 and how the government responds. We have all been so preoccupied with living our lives that many of us have missed out on those genuine, happy moments with our loved ones. It is due to our hectic schedules, scrambling to make ends meet, and racing to be in important meetings, among other things. The 
COVID-19 has now impacted how we express ourselves and maintain ties with our family and relatives. We can spend more time with our families and better plan our work which aids in the development of a brighter future for both our work and our families. Again, we can see that the weather is improving and the earth is becoming greener for us. So, while this shutdown has shown a short-term reduction in pollution, it is not a viable alternative for long-term climate change. We must consider a long-term and sustainable approach to safeguard the environment. Another critical point is if this little period of human noninterference can positively impact our atmosphere; if we try our hardest to save nature, we may be able to restore the earth's former glory. Finally, we can declare that we still have control over the situation to preserve ourselves and the world.

\section{LIMITATIONS AND FUTURE DIRECTIONS}

The lack of past studies, literature, and expertise is the study's first and most serious shortcoming. The research problem is one-of-a-kind and novel in its format. The qualitative approach was used exclusively by the researchers, which is the second constraint. To establish the fact in general, researchers recommend using a mixed technique approach. Another key weakness of the study is its location; researchers researched one division (Sylhet) of Bangladesh, which may not represent other cultures and countries' opinions. As a result, it is difficult to generalize the study's findings; additional research should be undertaken in various divisions of Bangladesh, countries, and cultures. Another drawback is that only qualitative discussion has been used using qualitative data. A future idea will be to create quantitative and mixed methods research to get significant findings.

\section{REFERENCES}

[1] Wang, C., Horby, P. W., Hayden, F. G. \& Gao, G. F., (2020). A novel coronavirus outbreak of global health concern. The Lancet, 395(10223), 470-473

[2] Rahaman, M. S., Rahman, M. M., \& Moral, I. H. (2020). Informative knowledge and challenges of home quarantine during COVID-19 in Bangladesh. International Journal of Technology Transfer and Commercialisation, 17(4), 354-367.

[3] Rahman M. M, Uddin M. B. Chowdhury M. S, Rahaman M. S. (2021a) "Psychological Status of Private Commercial Bank Employees in Bangladesh during COVID-19". Journal of Business Strategy Finance and Management, 2(2).

[4] Salamzadeh, A., \& Dana, L. P. (2020). The coronavirus (COVID-19) pandemic: challenges among Iranian startups. Journal of Small Business \& Entrepreneurship, 33(5), 489-512.

[5] Shereen, M. A., Khan, S., Kazmi, A., Bashir, N., \& Siddique, R. (2020). COVID-19 infection: Origin, transmission, and characteristics of human coronaviruses. Journal of advanced research, 24, 91

[6] Cascella, M., Rajnik, M., Cuomo, A., Dulebohn, S. C. and Di Napoli, R., (2020). Features, evaluation and treatment coronavirus (COVID-19). In Statpearls [internet]. StatPearls Publishing.

[7] Goyal, P., Choi, J. J., Pinheiro, L. C., Schenck, E. J., Chen, R., Jabri, A. and Hoffman, K. L., (2020). Clinical characteristics of Covid-19 in New York City. New England Journal of Medicine.

[8] Lu, R., Zhao, X., Li, J., Niu, P., Yang, B., Wu, H..... \& Bi, Y. (2020). Genomic characterisation and epidemiology of 2019 novel coronavirus: implications for virus origins and receptor binding. The Lancet, 395 (10224), 565-574.

[9] Nishiura, H., Jung, S. M., Linton, N. M., Kinoshita, R., Yang, Y., Hayashi, K.and Akhmetzhanov, A. R.,(2020). The extent of transmission of novel coronavirus in Wuhan, China, 2020.

[10] Xiang, Y. T., Yang, Y., Li, W., Zhang, L., Zhang, Q., Cheung, T. \& Ng, C. H., (2020). Timely mental health care for the 2019 novel coronavirus outbreak is urgently needed. The Lancet Psychiatry, 7(3), 228-229

[11] Institute of Epidemiology, Disease Control (IEDCR), (2020) Research and "করোনা ইনফো". corona.gov.bd. (retrieved March 27 2020). 
[12] bdnews24.com. (2020). Bangladesh Bank announces 'incentives" for bankers working during viruslockdown.'https://bdnews24.com/business/2020/04/13/bangladesh-bank-announces-incentivesfor-bankers-workingduring- virus-lockdown. Accessed 06 July 2020

[13] Pereira, J., Braga, V., Correia, A., \& Salamzadeh, A. (2021). Unboxing organisational complexity: how does it affect business performance during the COVID-19 pandemic?. Journal of Entrepreneurship and Public Policy, 10(3), 424-444.

[14] Marotti de Mello, A., Schiller, K.J.F., Ghosh, B., Roy, J. \& Swilling, M. (2021), "Call for papers: sustainability transitions in the Global South - learnings from COVID-19 and future directions", Revista de Gestão, 28(1), 100-103.

[15] Rahman, M., \& Rahaman, S. (2021b). Home Quarantine Challenges and Psychological Status of Bangladeshi University Students during COVID-19. Journal of Education, Management and Development Studies, 1(2), 1-9.

[16] Kawamorita, H., Salamzadeh, A., Demiryurek, K., \& Ghajarzadeh, M. (2020). Entrepreneurial universities in times of crisis: Case of COVID-19 pandemic. Journal of Entrepreneurship, Business and Economics, 8(1), 77-88.

[17] Hameed, N. S. S., Salamzadeh, Y., Rahim, N. F. A., \& Salamzadeh, A. (2021). The impact of business process reengineering on organizational performance during the coronavirus pandemic: moderating role of strategic thinking. foresight.

[18] Burke M. (2020). Covid-19 reduces economic activity, which reduces pollution, which saves lives". G-FEED.org. 8 March 2020.

[19] Cathy Li\&Farah Lalani. (2020). The COVID-19 pandemic has changed education forever. Retrieved From https://www.weforum.org/agenda/2020/04/coronavirus-education-global-covid19-onlinedigital-learning/

[20] Brani, O., Hefferon, K., Lomas, T., Ivtzan, I., \& Painter, J. (2014). The impact of body awareness on subjective wellbeing: The role of mindfulness. International Body Psychotherapy Journal, 13(1), 95-107.

[21] Lomas, T., Roache, A., Rashid, T., \&Jarden, A. (2019). Developing ethical guidelines for positive psychology practice: An on-going, iterative, collaborative endeavour. The Journal of Positive Psychology, 1-6.

[22] Mauricio Cárdenas, (2020), Looking at the Bright Side: 10 Positive Effects of the Pandemic.

[23] Vipin Thomas, (2020), 8 Positive Impacts to look forward to post the COVID-19 pandemic, Retrieved Fromhttps://surveysparrow.com/blog/positive-impacts-to-look-forward-to-post-covid-19pandemic/

[24] Magomedov, I. A., Khaliev, M. S., \&Khubolov, S. M. (2020, November). The negative and positive impact of the pandemic on education. In Journal of Physics: Conference Series, 1691(1), p. 012134.

[26] Ming, W., Zhou, Z., Ai, H., Bi, H., \&Zhong, Y. (2020). COVID-19 and air quality: Evidence from China. Emerging Markets Finance and Trade, 56(10), 2422-2442.

[25] Khan, I., Shah, D., \& Shah, S. S. (2020). COVID-19 pandemic and its positive impacts on environment: an updated review. International Journal of Environmental Science and Technology, 1-10.

[27] Lau, H., Khosrawipour, V., Kocbach, P., Mikolajczyk, A., Schubert, J., Bania, J., \& Khosrawipour, T. (2020). The positive impact of lockdown in Wuhan on containing the COVID-19 outbreak in China. Journal of travel medicine, 27(3), taaa037.

[28] Balmford, B., Annan, J. D., Hargreaves, J. C., Altoè, M., \& Bateman, I. J. (2020). Cross-country comparisons of COVID-19: Policy, politics and the price of life. Environmental and Resource Economics, 76(4), 525-551.

[29] Kroll, T., Barbour, R., \& Harris, J. (2007). Using focus groups in disability research. Qualitative health research, 17(5), 690-698.

[30] Dana, L. P., \& Dumez, H. (2015). Qualitative research revisited: epistemology of a comprehensive approach. International Journal of Entrepreneurship and Small Business, 26(2), 154-170.

[31] Guest, G., Bunce, A., \& Johnson, L. (2006). How many interviews are enough? An experiment with data saturation and variability. Field Methods. 18, 59.

[32] Rahaman, M.S., Reza, S.M.A., Rahman, M.M.,\& Solaiman Chowdhury, M. (2021), "A deplorable community in Bangladesh: tea garden workers", Journal of Enterprising Communities: People and Places in the Global Economy, 15(4), 548-566.

[33] Li, C., \& Lalani, F. (2020, April). The COVID-19 pandemic has changed education forever. This is how. In World economic forum, 29(1) 
[34] Syifa Fadiyah (April 3, 2020) "5 Benefits of ERP for Home Based-Learning during Covid-19 Pandemic.

[35] Harvath, T. A., Mongoven, J. M., Bidwell, J. T., Cothran, F. A., Sexson, K. E., Mason, D. J., \& Buckwalter, K. (2020). Research priorities in family caregiving: Process and outcomes of a conference on family-centered care across the trajectory of serious illness. The Gerontologist, 60(Supplement_1), S5-S13.

[36] Henriques, S. F., Dhakan, D. B., Serra, L., Francisco, A. P., Carvalho-Santos, Z., Baltazar, C., ... \& Ribeiro, C. (2020). Metabolic cross-feeding in imbalanced diets allows gut microbes to improve reproduction and alter host behaviour. Nature communications, 11(1), 1-15.

[37] Susanta Nanda IFS, (2020, April 19). Coronavirus lockdown: Video of penguins roaming freely on Cape Town street goes viral. Twitter is amazed, Retrieved Fromhttps://www.indiatoday.in/amp/trending-news/story/coronavirus-lockdown-video-of-penguinsroaming-freely-on-cape-town-street-goes-viral-twitter-is-amazed-1668601-2020-04-19

[38] Tareq Rafi Bhuiyan (July 18, 2020) "Post-Covid era megatrends: The new normal" https://thefinancialexpress.com.bd/views/post-covid-era-megatrends-the-new-normal-1595008890

[39] Frare, A.B. \& Beuren, I.M. (2021). Job autonomy, unscripted agility and ambidextrous innovation: analysis of Brazilian startups in times of the Covid-19 pandemic", Revista de Gestão, 28(3), 263278

\section{Article history:}

Received 23 November 2021

Accepted 17 December 2021 